\title{
'Homemade': the phenotypic diversity of coral reef damselfish populations is driven by the local environment
}

\author{
CHIA-TING CHEN ${ }^{1, \dagger, \sharp}$, VANESSA ROBITZCH ${ }^{2,3, \dagger}$, NICOLAS STURARO $^{1}$, \\ GILLES LEPOINT ${ }^{1}$, MICHAEL L. BERUMEN² and BRUNO FRÉDÉRICH ${ }^{4 *,}$ \\ ${ }^{1}$ Laboratoire d'Océanologie, FOCUS, Université de Liège, B-4000 Liège, Belgium \\ ${ }^{2}$ Red Sea Research Center, Division of Biological and Environmental Science and Engineering, King \\ Abdullah University of Science and Technology, Thuwal, 23955-6900, Saudi Arabia \\ ${ }^{3}$ Instituto de Ciencias Ambientales y Evolutivas, Facultad de Ciencias, Universidad Austral de Chile, $E$ \\ Pugin, Casilla 567, Valdivia, Chile \\ ${ }^{4}$ Laboratoire de Morphologie Fonctionnelle et Evolutive, FOCUS, Université de Liège, B-4000 Liège, \\ Belgium
}

Received 11 January 2019; revised 14 March 2019; accepted for publication 14 March 2019

\begin{abstract}
Documenting phenotypic variation among populations is crucial for our understanding of micro-evolutionary processes. To date, the quantification of trophic and morphological variation among populations of coral reef fish at multiple geographical scales remains limited. This study aimed to quantify diet and body shape variation among four populations of the damselfish Dascyllus abudafur living in different environmental conditions from the central Red Sea and from Madagascar. Stomach content analyses showed that one adaptive response of $D$. abudafur inhabiting turbid waters is a trophic shift from almost exclusive zooplanktivory to a diet consisting of planktonic and benthic prey. Our morphometric data reveal differences in cephalic profile and body shape among populations, in agreement with this variation in trophic strategy. Isotopic diversity and body shape disparity vary among populations and we thus demonstrate that coral reef fish populations are not equal in terms of phenotypic diversity among sites and regions. Finally, our comparative analysis reveals that the main axes of body shape variation among populations are shared at both small (Red Sea sites) and large (Madagascar and Red Sea sites) spatial scales. This study raises new questions about the factors governing the direction of response to selection in this fish species.
\end{abstract}

ADDITIONAL KEYWORDS: body shape - ecomorphology - geometric morphometrics - geographical variation microevolution - Pomacentridae - Red Sea - stable isotopes - stomach contents - Western Indian Ocean.

\section{INTRODUCTION}

Natural selection operates on phenotypic variation among populations, leading to their differentiation and the evolution of new species (Rundell \& Price, 2009). Biotic and abiotic factors select morpho-functional traits that are favourable for exploitation of certain resources (Wainwright \& Bellwood, 2002; Pereira et al.,

\footnotetext{
*Corresponding author: E-mail: bruno.frederich@uliege.be These authors contributed equally to this study.

¥Present address: Aix-Marseille Université and Université de Toulon, Mediterranean Institute of Oceanography (MIO), CNRS/INSU, IRD, UM 110, 13288 Marseille Cedex 9, France.
}

2014). In fishes, several ecomorphological studies have demonstrated that morphological traits, such as body and head shape, are directly linked to feeding and swimming performance and thus predict interspecific patterns of resource use (e.g. Liem, 1993; Fulton \& Bellwood, 2005; Aguilar-Medrano et al., 2011, 2013). Similarly, documenting phenotypic variation among populations and identifying the factors influencing these patterns of phenotypic diversity may help in understanding micro-evolutionary processes (Bolnick et al., 2011).

Coral reefs are heterogeneous environments that can lead to the differentiation of a great number of 
phenotypes and species (Shulman, 1984; Whitney et al., 2018). The structural complexity and high productivity of coral reefs provide numerous resources and microhabitats, and therefore various axes of niche differentiation (Monismith et al., 2006; Reidenbach et al., 2006). In coral reef fishes, intraspecific phenotypic variation is frequently associated with sexual dimorphism (e.g. Robertson, 1985) and/or with ontogenetic shifts (e.g. Frédérich et al., 2008, 2012a). Recent studies have also documented variation of trophic traits among populations of coral reef fishes (Frédérich et al., 2012b; Piñeros et al., 2015). For example, Piñeros et al. (2015) showed that individuals from the damselfish Abudefduf saxatilis, living in an environment with high planktonic biomass, have a more upward-oriented mouth compared with other individuals living with low planktonic biomass. Such morphological variation related to diet or habitat is even detected at spatial scales below $100 \mathrm{~m}$ and across coastal gradients (Fulton et al., 2013; Binning et al., 2014; Binning \& Roche, 2015). To the best of our knowledge, no previous study has compared trophic and morphological traits among populations of coral reef fishes at both small and large spatial scales. Such a comparative framework will help improve our understanding of the magnitude and repeatability of adaptive responses in reef fishes.

Dascyllus abudafur (Borsa et al., 2014) is a small (5-10 cm total length), coral-dwelling damselfish, which forms hierarchical size-structured social groups in branching corals (e.g. genera Acropora or Pocillopora) seeking protection from predators (Sale, 1971). This species is geographically widely distributed, abundant and lives at depths of 2-20 m within Indian Ocean reefs. Initially described as a zooplanktivorous species (Fricke \& Holzberg, 1974; Randall \& Allen, 1977; Coates, 1982), D. abudafur as well as its sister species Dascyllus aruanus (Borsa et al., 2014) supplement their diet by feeding on small benthic crustaceans and/ or filamentous algae (Frédérich et al., 2010; Gajdzik et al., 2016), broadening their fundamental trophic niche and thus allowing for some degree of intraspecific variability and/or trophic specialization of individuals.

The present study aims to quantify phenotypic variation among populations of D. abudafur at small (central Red Sea, along a cross-shelf gradient) and large spatial scales (between the Red Sea sites and the site of Toliara, Madagascar,). The reef sites studied differ in their environmental conditions (i.e. water turbidity, wave exposure and current speed), and thus we expected to find trophic and morphological divergences among fish populations. Turbid waters may negatively impact the ability of zooplanktivorous species to capture elusive prey (Johansen \& Jones, 2013). Thus, we first examined stomach contents with the expectation that populations of $D$. abudafur living in turbid waters (e.g. Toliara lagoon) would capture proportionally more benthic prey than in clearer areas (e.g. Red Sea sites). Isotopic niche (variance of isotopic values) is generally used as a proxy for trophic niche (Newsome et al., 2007). Stable isotope analyses can be used to characterize trophic heterogeneity based on the isotopic variability within communities, species or populations (Layman et al., 2007; Newsome et al., 2007). Here, we hypothesize that populations from different sites may show different trophic strategies that would be reflected in their isotopic variance. In parallel, we explored body shape variation and expected to find morphological divergence among populations of D. abudafur, which would be associated with variation in feeding strategies. Finally, we compared the main axes of morphological variation at large and small spatial scales to assess the level of conservatism in phenotypic divergence.

\section{MATERIAL AND METHODS}

\section{SAMPLING AND STUDY SITES}

Dascyllus abudafur specimens were collected at reef sites from the central Red Sea in February and March 2015 selected along a cross-shelf gradient off the Saudi Arabian coast (Fig. 1; Table 1, from shore to offshore from the shelf edge): Abu Shosha (ASU, inshore), Al Fahal (AFA, on the edge of the shelf) and Shib Nazar (SNA, offshore from the shelf-edge); and from Madagascar, in October 2006, at the lagoon of the Great Reef of Toliara (TL, inner reef slope of the barrier reef).

In the central Red Sea, 101 D. abudafur specimens were collected at these three sites from six similarsized $(20-30 \mathrm{~cm})$ Pocillopora verrucosa coral colonies per site. At each site, 28-37 specimens of D. abudafur were collected using hand nets, forceps, plastic bags and clove-oil (Table 1). Fish samples were taken from the northern sheltered, leeward side of the reef (patchy and sandy lagoons) at similar depths (10-12 $\mathrm{m}$ for ASU and AFA, and $14 \mathrm{~m}$ for SNA). Only coral colonies exclusively inhabited by $D$. abudafur as pomacentrid coral-dwellers were sampled. In Madagascar, the same collection techniques (except that quinaldine was used instead of clove-oil) and requisites were chosen to sample three inshore, sheltered Acropora coral colonies from the same site at $8 \mathrm{~m}$ depth. Sampling took place only in the afternoon, prior to sunset, to increase the likelihood of finding undigested prey. All fishes were euthanized via an overdose of MS-222 (tricaine-methanosulfonate), as per article 14 of the European Union Directive (2010/63/EU) covering the protection of animals used for scientific purposes, and stored in $70 \%$ ethanol. The standard length (SL) of each individual was measured to the nearest $1 \mathrm{~mm}$ using a Vernier calliper (Table 2). 


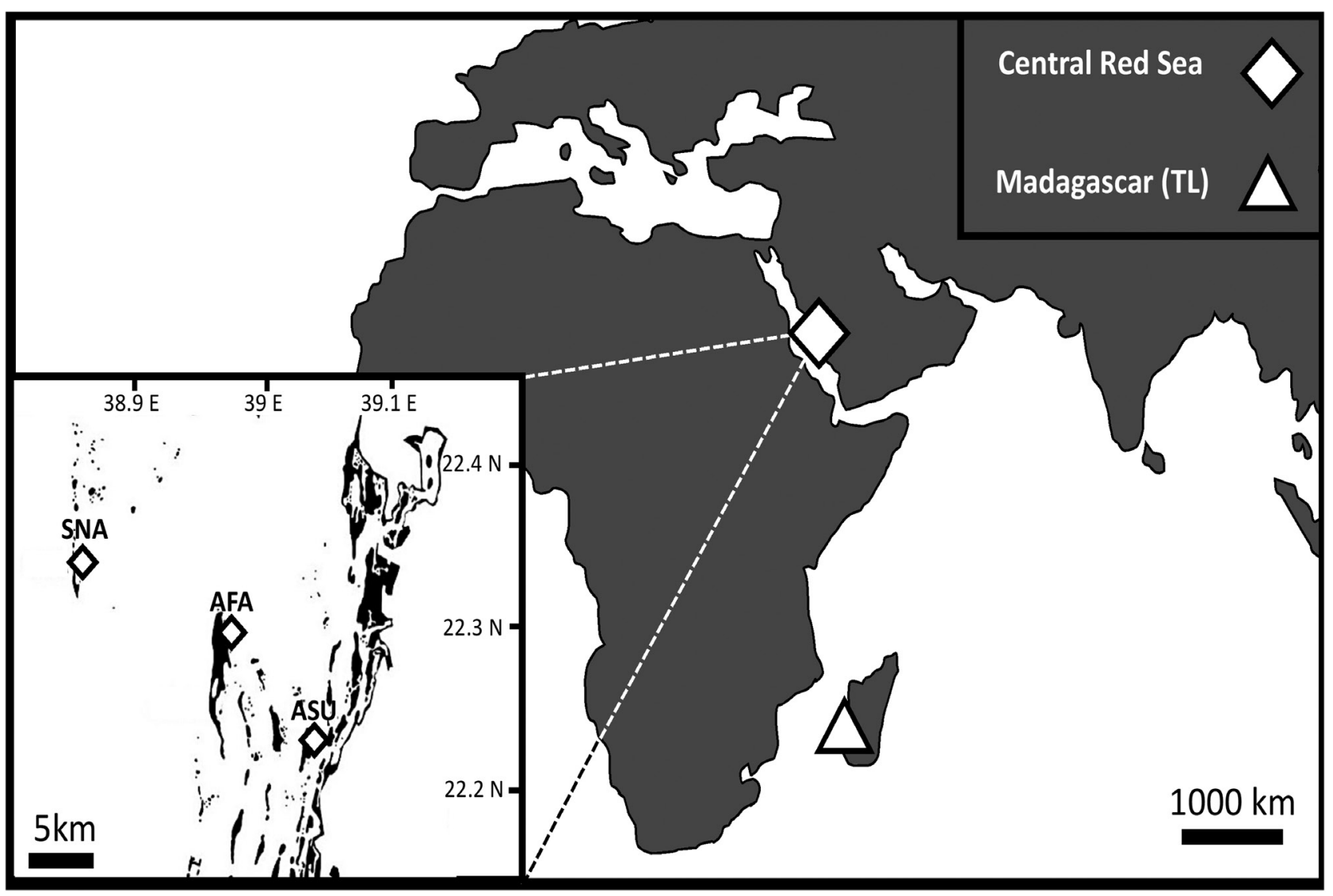

Figure 1. Sampling sites of Dascyllus abudafur from the central Red Sea (white diamonds) and Madagascar (white triangle). The zoomed section indicates the reef sites sampled in the central Red Sea, each on the leeward side of the reef, along a cross-shelf gradient (ASU, AFA and SNA, from shore to shelf-edge, respectively; see Table 1 for abbreviations and coordinates).

Table 1. Environmental characterization of Dascyllus abudafur sampling sites in the Red Sea and in Madagascar

\begin{tabular}{|c|c|c|c|c|c|}
\hline Site & $\begin{array}{l}\text { Geographical } \\
\text { coordinates }\end{array}$ & Depth (m) & $\begin{array}{l}\text { Distance from } \\
\text { the coast }(\mathrm{km})\end{array}$ & $\begin{array}{l}\text { Water visibility, } \\
\text { mean } \pm \mathrm{SD}(\mathrm{m})\end{array}$ & $\begin{array}{l}\text { Current velocity, } \\
\text { mean } \pm \mathrm{SD} \\
(\mathrm{m} / \mathrm{s})\end{array}$ \\
\hline $\begin{array}{l}\text { Abu Shosha } \\
\text { (ASU) }\end{array}$ & $\begin{array}{l}22^{\circ} 18^{\prime} 17.74^{\prime \prime} \mathrm{N} \\
39^{\circ} 02^{\prime} 57.39^{\prime \prime} \mathrm{E}\end{array}$ & 10 & 3 , inshore & $25.2 \pm 6.7$ & $0.05 \pm 0.02$ \\
\hline $\begin{array}{l}\text { Al Fahal } \\
\text { (AFA) }\end{array}$ & $\begin{array}{l}22^{\circ} 18^{\prime} 24.54^{\prime \prime} \mathrm{N} \\
38^{\circ} 57^{\prime} 47.25^{\prime \prime} \mathrm{E}\end{array}$ & 10 & 10, midshore & $22.1 \pm 4.5$ & $0.05 \pm 0.01$ \\
\hline $\begin{array}{l}\text { Shi'b Nazar } \\
\text { (SNA) }\end{array}$ & $\begin{array}{l}22^{\circ} 20^{\prime} 51.96^{\prime \prime} \mathrm{N} \\
38^{\circ} 51^{\prime} 09.42^{\prime \prime} \mathrm{E}\end{array}$ & 14 & 25 , offshore & $35.8 \pm 5.6$ & $0.04 \pm 0.01$ \\
\hline Toliara (TL) & $\begin{array}{l}23^{\circ} 22^{\prime} 34.80^{\prime \prime} \mathrm{S} \\
43^{\circ} 38^{\prime} 15.00^{\prime \prime} \mathrm{E}\end{array}$ & 8 & 1 , inshore & $12.0 \pm 5.3$ & $0.05 \pm 0.03$ \\
\hline
\end{tabular}

Sampling sites were ASU, AFA and SNA (from shore to shelf-edge) in the central Red Sea and TL in the lagoon of Toliara (Madagascar), Indian Ocean. Information for environmental characterization of Toliara was obtained from Arfi et al. (2007).

For the three Red Sea sites, water turbidity and current velocity were measured over a 12 -month period (2015) by respectively using a Secchi disc (five consecutive days during each new moon period of each month) and three Nortek AS Aquadopp Doppler current meters (Vangkronken, one per site) over 0.5 -m bins at 10 -min sampling intervals over that period. Averaged values were calculated for each site 
Table 2. Dascyllus abudafur caught in the Red Sea (ASU, AFA and SNA) and in Madagascar (TL) with data for standard length range (minimal and maximal values) and the number of individuals used for stomach content, stable isotope and shape data analyses

\begin{tabular}{lclll}
\hline Site & Standard length $(\mathrm{mm})$ & Stomach contents & Stable isotopes & Shape data \\
\hline ALL & $8.8-57.8$ & $N=138$ & $N=138$ & 137 \\
& & $N_{0}=6$ & $N_{0}=12$ & \\
Abu Shosha (ASU) & $11.8-49.4$ & $N=28$ & $N=28$ & 27 \\
& & $N_{0}=1$ & $N_{0}=4$ \\
Al Fahal (AFA) & $13.3-45.8$ & $N=37$ & $N=37$ & 37 \\
& & $N_{0}=4$ & $N_{0}=5$ & \\
Shi'b Nazar (SNA) & $8.8-57.8$ & $N=36$ & $N=36$ & 36 \\
Toliara Lagoon (TL) & $10.3-52.1$ & $N_{0}=1$ & $N_{0}=3$ & 37 \\
& & $N=37$ & $N=37$ & \\
\hline
\end{tabular}

' $N$ ' refers to the number of individuals, while ' $N_{0}$ ' is the number of individuals with an empty stomach or the number of individuals with too little muscle matter for accurate measurements of its isotopic composition.

(Table 1). Similar data were retrieved from literature for the Toliara site in Madagascar (Arfi et al., 2007; Bruggemann et al., 2012; Chevalier et al., 2015). Environmental conditions at each site are reported in Table 1. The Great Reef of Toliara site has been heavily impacted as a result of overfishing (Andréfouët et al., 2013). Additionally, the runoff of terrigenous sediments due to massive deforestation and high levels of eutrophication (Andréfouët et al., 2013) have made the waters of Toliara lagoon turbid (visibility of 6.4-14.3 m; Arfi et al., 2007). Conversely, all Red Sea sites have mostly clear, oligotrophic waters (mean visibility of $27.6 \mathrm{~m}$, range $14-37 \mathrm{~m}$, Table 1 ) and the variation in water visibility correlates directly with variations in the concentration of chlorophyll-a (Roik et al., 2016). At Toliara, the tidal range is up to $2.9 \mathrm{~m}$ (Chevalier et al., 2015) whereas the tides are relatively small $(\sim 15-20 \mathrm{~cm})$ in the central Red Sea, especially between Jeddah and Port Sudan (Pugh et al., 2019).

\section{TROPHIC VARIATION}

\section{Stomach content analysis}

All dietary items of the stomachs of 95 individuals from the Red Sea were identified using a Leica MS5 stereoscopic microscope, and categorized into prey groups (Barel, 1982): planktonic copepods, other planktonic crustaceans, ascidian larvae and eggs, benthic copepods, other benthic crustaceans (isopods, amphipods, water mites and polychaetes), and algae or plant detritus. Published data on the stomach contents of 37 individuals of the D. abudafur population from Toliara (Frédérich et al., 2010, same methodology as presented herein) were used for comparative analyses. We quantified relative numerical abundance $(\% N$ : number of items in each prey category, expressed as a percentage of the total number of items in all prey categories) and the frequency of occurrence $(\% F$ : percentage of all non-empty stomachs in which a component was found) of each food item in the stomachs (Hyslop, 1980). The $\% N$ data were arcsine-square root transformed before analysis to meet the normality assumption (Shapiro Wilks' test, after transformation). The \%N of planktonic prey was regressed on the SL of fish to test the null hypothesis of no relationship between foraging tactics and fish size (Frédérich et al., 2010). Two of the four populations did not show this linear relationship (see Results). Therefore, the null hypothesis of no difference in foraging tactics among different populations was tested using a one-way ANOVA followed by post hoc multiple comparison tests (Tukey test).

\section{Stable isotope analysis}

A muscle sample $\left(\sim 1 \mathrm{~cm}^{3}\right)$ was taken from each individual fish (preserved in 70\% ethanol) and was dehydrated at $50{ }^{\circ} \mathrm{C}$ for $48 \mathrm{~h}$ before being ground to a homogeneous powder. Although we acknowledge that some preservation methods may impact the isotopic composition of muscle tissues (Kaehler \& Pakhomov, 2001; Vizza et al., 2013), a thorough literature review suggested that preservation of fish samples in ethanol does not influence the original isotopic variance of epidermal (Barrow et al., 2008) and muscle tissues (Kelly et al., 2006; Manetta et al., 2011; Fleming et al., 2011). Stable isotope ratios of carbon and nitrogen were measured using an isotope ratio mass spectrometer (IsoPrime100, Isoprime, UK) coupled in continuous flow to an elemental analyser (vario MICRO cube, Elementar, Germany). Stable isotope ratios were expressed as conventionally $\delta$ values in per 
mil (\%o) (Coplen, 2011). Certified reference materials from the International Atomic Energy Agency (IAEA, Vienna, Austria) were ammonium sulphate (IAEA- $\mathrm{N}_{1}, \delta^{15} \mathrm{~N}=0.4 \pm 0.3 \%$ ) and sucrose (IAEA CH-6, $\delta^{13} \mathrm{C}=-10.4 \pm 0.3 \%$ ). Both reference materials were calibrated against the international references Vienna Pee Dee Belemnite for carbon and atmospheric air for nitrogen. Routine measurements of internal laboratory standards indicate precisions (standard deviations) of $0.2 \%$ for $\delta^{13} \mathrm{C}$ and $0.3 \%$ for $\delta^{15} \mathrm{~N}$.

Beyond the variation in the type of prey selected by $D$. abudafur, we were also interested in the heterogeneity of trophic strategies present in each population. The study of individuals' dispersion in 'isotopic space', which is defined by the plane formed with isotopic values of carbon and of nitrogen, provides relevant information on the partitioning of trophic resources within populations (Jackson et al., 2011; Newsome et al., 2012). Here, we first assessed the trophic diversity of each population by using two methods to quantify their isotopic richness: (1) a standard ellipse (SE) and (2) a convex envelope (convex hull) representing the core isotopic niche and the total isotopic richness, respectively (Jackson et al., 2011). Areas of the ellipses associated with each population $\left(\mathrm{SEA}_{\mathrm{B}}\right)$ were computed using Bayesian modelling $\left(10^{6}\right.$ iterations), and direct pairwise comparisons of $\mathrm{SEA}_{\mathrm{B}}$ were performed. Isotopic niche parameters were computed using SIBER (Stable Isotope Bayesian Ellipses in R; Jackson et al., 2011), a part of the R-package SIAR [Stable Isotope Analysis in R, v.4.2, fitted in R 3.1.3 (R Development Core Team, 2013)]. Model solutions were presented using credibility intervals of probability density function distributions.

Two other metrics of isotopic diversity were then computed in a standardized multidimensional space: isotopic divergence (IDiv) and isotopic dispersion (IDis; Cucherousset \& Villéger, 2015). Both indices vary between 0 and 1 . IDiv infers the deviance from all individuals to the centre of gravity of the convex hull. IDiv is minimal when most individuals are close to the centre of gravity of the convex hull (i.e. when individuals with extreme isotopic values are rare in a population), but is close to 1 when fish with extreme isotopic values dominate the population. IDis can be seen as a multidimensional variance metric. IDis is close to 0 when all organisms have the same isotopic values and increases to 1 when most of the points are far from the centre of gravity of the group of points (i.e. when organisms tend to have contrasted isotopic values). The calculation routines for IDis and IDiv are provided by Cucherousset \& Villéger (2015) (freely available at: http://villeger.sebastien.free.fr/R\%20 scripts/si_div.r).

Using these four metrics, we first aimed to compare the raw isotopic diversity among the four populations of D. abudafur. However, body size variation within a population explains some of the isotopic variance (see Results; Frédérich et al., 2010). Consequently, we repeated those calculations using size-corrected isotopic data obtained through residuals of linear regressions.

\section{MORPHOLOGICAL VARIATION}

Procrustes-based geometric morphometric methods were used to quantify fish body shape variation. Each specimen was photographed in lateral view using a Canon EOS 6D camera mounted on a stem. TPSDig2, a computer program written by F. J. Rohlf (freely available at: http://life.bio.sunysb.edu/morph/), was used to digitize 21 homologous landmarks (LMs) to capture body shape (Fig. 2). All details regarding the generation of shape data are provided in Frédérich \& Vandewalle (2011). All LMs are described in AguilarMedrano et al. (2011) and Frédérich et al. (2014). The centroid body size (CS) was computed as the square root of the sum of the squares of the distances from all LMs to their centroid (Bookstein, 1991).

Statistical analyses were performed to examine the patterns of shape divergences among D. abudafur populations. First, a Procrustes ANOVA followed by pairwise comparisons of Procrustes distances

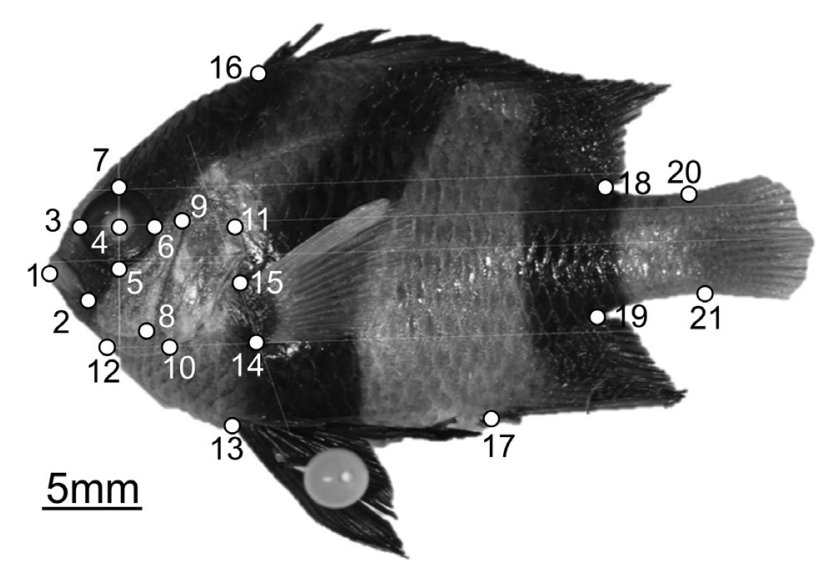

Figure 2. Homologous landmarks (LMs) used to define the overall body shape of Dascyllus abudafur: (1) anterior extremity of the premaxilla; (2) posterior extremity of the maxillary; (3) anterior extremity of the eye; (4) centre of the eye; (5-7) lower, posterior and superior extremity of the eye; (8) postero-ventral corner of the preoperculum; (9) upper extremity of the preopercular bone; (10) ventral extremity of the subopercle; (11) most supero-dorsal margin of the opercle; (12) base of the isthmus; (13) insertion of the pelvic fin; (14) lower and (15) upper insertion of the pectoral fin; (16) anterior and (18) posterior insertion of the dorsal fin; (17) anterior and (19) posterior insertion of the anal fin; (20) dorsal and (21) ventral base of the caudal fin. 
were performed to test if body shape differs among populations (Collyer et al., 2015). Then, a canonical variate analysis (CVA) was carried out to highlight the main axes of shape variation differentiating the four populations. Deformation grids generated by the 'Thinplate Spline (TPS)' algorithm were used to visualize the shape variation along the CVs axes. The program MorphoJ (Klingenberg, 2011) was used for regressions, and CVA and TPS analyses while a Procrustes ANOVA (permutation test, 9999 iterations) was performed in the R-package geomorph (Adams \& Otárola-Castillo, 2013).

Similarly to the exploration of isotopic variance, we compared the level of shape diversity (i.e. disparity) among populations. We calculated the level of shape disparity based on Procrustes variance (Zelditch et al., 2012) and performed pairwise comparisons (permutation test, 9999 iterations) between populations using the function morphol.disparity in the R-package geomorph (Adams \& Otárola-Castillo, 2013). Then, the SpaceAngle8 software from the IMP series (Zelditch et al., 2012) was used to compare the main axes of shape variation at large spatial scale (samples from all four populations) and at small spatial scale (samples from the three Red Sea populations). Detailed information about this test is provided in Zelditch et al. (2012). With this test, results are obtained by bootstrapping procedures $(N=1600)$ and the angle between hyperplanes (here defined by the first three principal components of shape variables) is considered significant if it exceeds the bootstrapped within-group variance at $95 \%$ confidence. Additionally, we performed a Mantel test to compare the structure of the covariance matrices at large and small spatial scales using the function mantel.test in the R-package ape (Paradis et al., 2004). These two different methods allowed us to test our prediction that the main axes of morphological variation are conserved at both spatial scales.

The growth of Dascyllus species is allometric (Frédérich \& Sheets, 2010) and thus size may explain a significant proportion of the shape variation. During preliminary analyses, we compared the allometric vectors (i.e. a comparison of slopes of the multivariate regression models between body shape and the logarithm of centroid size - logCS) among populations, which indicated that we could not reject the null hypothesis of the same pattern of allometric growth for each of the populations of $D$. abudafur. The residuals of regressions were therefore calculated using an identical linear model for all populations (Klingenberg, 2016) to obtain size-corrected shape data. All statistical analyses were finally repeated by using these new sets of shape data to investigate size-free shape variation among populations.

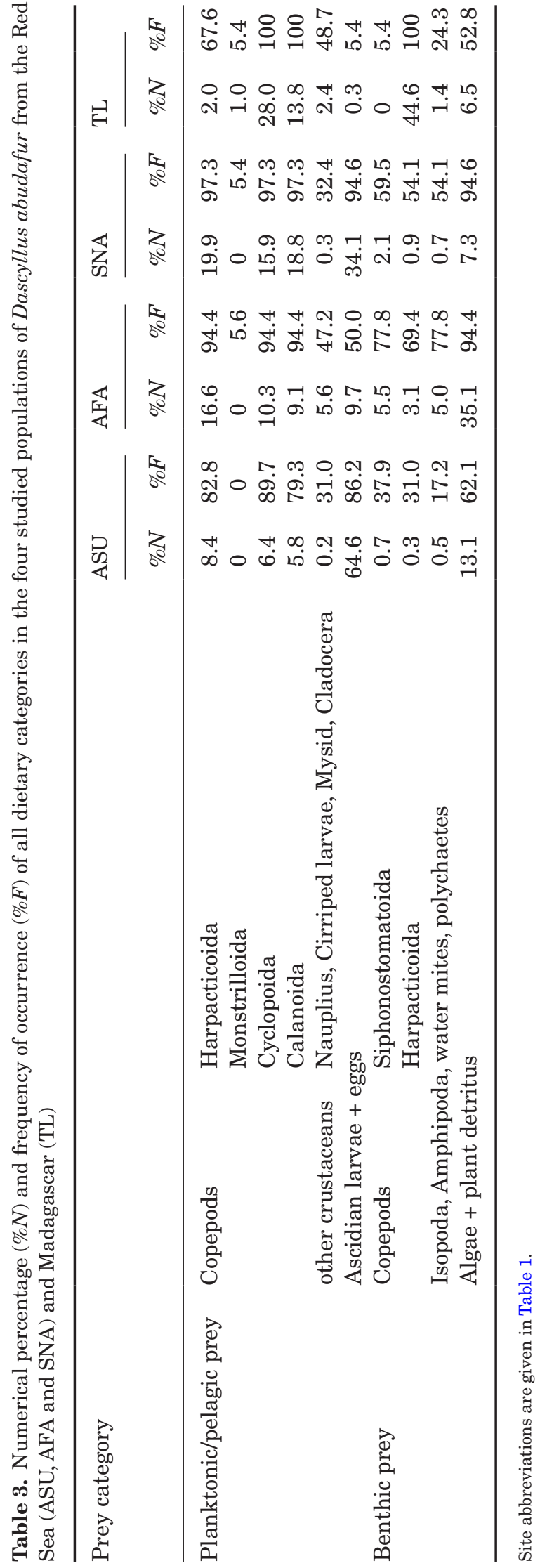




\section{RESULTS}

From a total of 138 specimens sampled (101 from the central Red Sea and 37 from Madagascar), 132, 126 and 137 were used for the analyses of stomach content, stable isotopes and body shape, respectively. Overall, D. abudafur showed variation in body size, ranging from 8.8 to $57.8 \mathrm{~mm}$ SL (Table 2).

\section{TROPHIC VARIATION}

\section{Stomach contents}

Only $4 \%$ (i.e. $N=6$ ) of all stomachs were empty. The remaining 132 were mainly filled with small planktonic and benthic crustaceans (Table 3). Ascidian larvae and eggs were also abundant, especially in individuals from ASU (Table 3). For fish specimens from the Red Sea, algae and plant detritus were regularly grazed (between 62 and 95\% of occurrence) and accounted for a mean of $18.5 \pm 14 \%$ of the diet in terms of abundance $(\% N)$. At two sites, the percentage of ingested planktonic prey was positively correlated with fish body size (TL: $r^{2}=0.1, P=0.03$; SNA: $r^{2}=0.3, P<0.001$ ). However, because this type of linear relationship was not observed for the ASU and AFA populations, we did not use an ANCOVA to compare populations.

Populations differed significantly in their feeding strategies (Kruskal-Wallis $K_{3,125}=65.8, P<0.001$ ). The two Red Sea populations of ASU (inshore) and SNA (offshore from the shelf-edge) fed more on zooplanktonic prey (mean $=87.4 \%$ of the diet) than the populations of AFA (Red Sea, shelf edge; mean $=54.8 \%$ of the diet) and TL (Madagascar; mean $=51.9 \%$ of the diet) (Fig. 3 ; Table 3). The AFA and TL populations did not differ in their proportions of ingested zooplanktonic prey (Tukey $Q=0.07, P=0.99$ ). At Toliara, $D$. abudafur ingested a large proportion of small benthic invertebrates (copepods, Harpacticoida) (100\% of animals examined) while individuals from AFA supplemented their diet by filamentous algae and plant detritus (Table 3). The SNA and ASU populations did not differ significantly in their feeding habit, mainly consuming zooplanktonic prey (Tukey $Q=0.2, P=1$ ).

\section{Stable isotope values}

The $\delta^{13} \mathrm{C}$ values of D. abudafur ranged from $-18.6 \%$ to $-14.3 \%$; the $\delta^{15} \mathrm{~N}$ values ranged between $5.4 \%$ and 9.7\%o. Populations from TL and AFA showed the largest variation along the $\delta^{13} \mathrm{C}$ axis (Fig.4).Across all populations, isotopic values varied with fish body size $\left(\delta^{15} \mathrm{~N}: r=0.7\right.$, $\left.P<0.001 ; \delta^{13} \mathrm{C}: r=-0.3, P<0.001\right)$. Large individuals had higher $\delta^{15} \mathrm{~N}$ values and more negative $\delta^{13} \mathrm{C}$ values than smaller individuals. However, the co-variation of $\delta^{13} \mathrm{C}$ and $\delta^{15} \mathrm{~N}$ with fish size differed significantly among populations (ANCOVA: $\delta^{13} \mathrm{C}-F_{3,127}=101.1, P<0.01$; $\left.\delta^{15} \mathrm{~N}-F_{3.127}=87.79, P<0.01\right)$. Linear models also revealed that the proportions of consumed zooplanktonic prey explained a fraction of the variation in $\delta^{15} \mathrm{~N}(r=0.2$, $P=0.05)$ and $\delta^{13} \mathrm{C}$ values $(r=-0.5, P=0.001)$.

Populations differed significantly in their isotopic richness (Fig. 5). The size of the standard ellipse $\left(\mathrm{SEA}_{\mathrm{B}}\right)$ and convex hull of the TL population were larger than those of Red Sea populations when using raw isotopic data (Fig. 5A; Supporting Information, Fig. S1a). However, the AFA population showed a similar level of isotopic richness to the TL population when using size-corrected isotopic data (Fig. 5B; Supporting Information, Fig. S1b). The SNA population was always characterized by the lowest level of isotopic richness. Table 4 provides the indices of isotopic divergence (IDiv) and dispersion (IDis) for each population. The Red Sea populations all had similar IDiv values, and which were lower than those from Toliara (Table 4). These results suggest that individuals with 'extreme' isotopic values were more abundant in the TL population than in the Red Sea populations. However, this divergence between the population of TL and the Red Sea populations is attenuated when using sizecorrected isotopic data. IDis values were in general rather low for each population (between 0.29 and 0.49). The AFA population had slightly higher IDis values, suggesting that this population had more contrasting isotopic values than the other populations.

\section{MORPHOLOGICAL VARIATION}

Morphological analyses performed on raw shape data and size-corrected shape data were in total agreement.

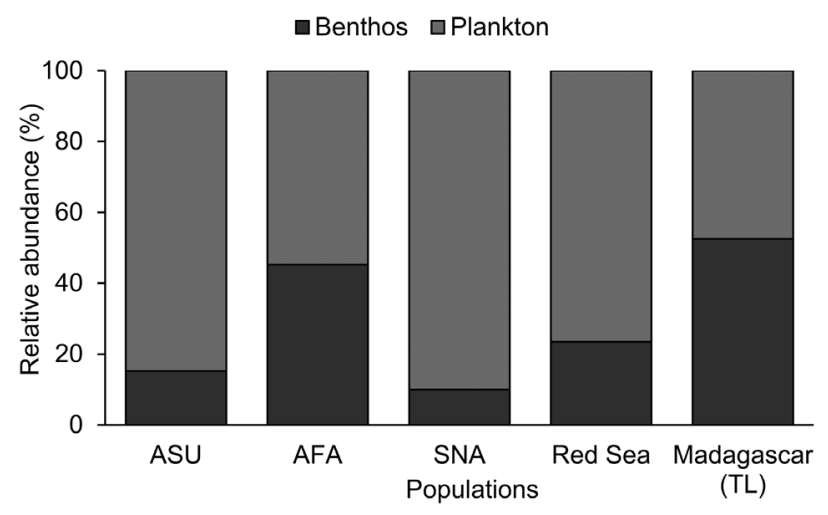

Figure 3. Bar chart of the relative abundance (\%) of planktonic (light grey) and benthic (dark grey) prey present in the stomachs of Dascyllus abudafur from sites in the central Red Sea (ASU, AFA and SNA, from shore to shelf-edge, respectively) and from Madagascar (TL). The column labelled as Red Sea represents mean values from the central Red Sea sites. Site abbreviations are given in Table 1. 
Hereafter, we mainly describe results obtained with raw shape data.

The four populations differed significantly in their mean body shape (Procrustes ANOVA - raw data: $F_{3,136}=24.29, P<0.001 ;$ size-corrected shape data: $\left.F_{3,136}=1.24, P<0.001\right)$. Pairwise comparisons based on Procrustes distances showed significant differences among the four populations (Table 5). When using raw shape data, the CV1 and CV2 axes represented 83.8\% and $10.7 \%$, respectively, of the total variation in body shape. The CV1 axis clearly distinguished between the population of Madagascar and those of the Red Sea (Fig. 6A). The main morphological variation captured by the two first CV axes concerned the size of the eye (LMs 3-7), the length of the dorsal fin (LMs 16-18), the length of the anal fin (LMs 17-19), the height of the body (LMs 16 and 13), the height of the operculum (LM 11), the insertion of the pectoral fin (LMs 14 and 15) and the size of the caudal peduncle (LMs 18-21). Red Sea individuals had proportionately larger eyes, shorter dorsal and anal fins, a higher operculum, and more vertical and anterior pectoral fin insertion than individuals from TL (Fig. 6B). The CV2 axis discriminated among the Red Sea populations, separating individuals of AFA from those of ASU and SNA. This axis was associated with variation in the orientation of the mouth (LMs 1 and 2), the size of the eye (LMs 3-7), the width of the operculum (LMs 10 and 11) and the angle of pectoral fin attachment (LMs 14 and 15) (Fig. 6B). The anterior part of the body was higher, eye size and the operculum were larger, and insertion of the pectoral fins was more posterior in individuals from AFA. The opening of the mouth was also oriented more ventrally in $D$. abudafur from

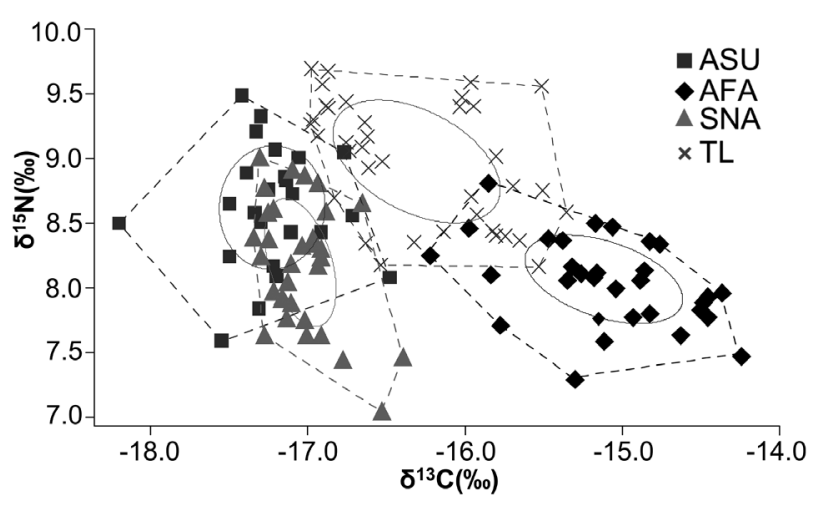

Figure 4. Isotopic values of $\delta^{15} \mathrm{~N}$ and $\delta^{13} \mathrm{C}$ for populations of Dascyllus abudafur from central Red Sea sites (ASU, AFA and SNA, from nearshore to offshore) and Madagascar (TL). The isotopic values of $\delta^{15} \mathrm{~N}$ and $\delta^{13} \mathrm{C}$ are displayed with convex envelopes (dotted outline) and standard ellipses of the $40 \%$ confidence interval. Sites are indicated by different symbols and the respective abbreviations are given in Table 1.
AFA compared to individuals from the two other Red Sea populations (Fig. 6B). CVA performed on sizecorrected shape data also allowed us to distinguish the TL population from those of the Red Sea along CV1, and the associated shape variation was similar (Supporting Information, Fig. S2).

Concerning the level of body shape disparity, the population from Toliara showed significantly higher Procrustes variance than all the Red Sea populations (Fig. 7, $P<0.001$ ). The AFA population showed a higher level of body shape disparity than ASU and SNA individuals when considering raw shape data (Fig. 7A) but this difference among the Red Sea populations was no longer present when using size-corrected shape data (Fig. 7B, $P>0.55$ ).

Whatever the shape dataset used, the structure of covariance matrices did not differ at either large or small spatial scales (Mantel tests - raw data: $Z=1.92 \mathrm{E}^{-07}, P<0.001$; size-corrected shape data: $\left.Z=5.27 \mathrm{E}^{-08}, P<0.001\right)$. Calculation of the angles

(a)

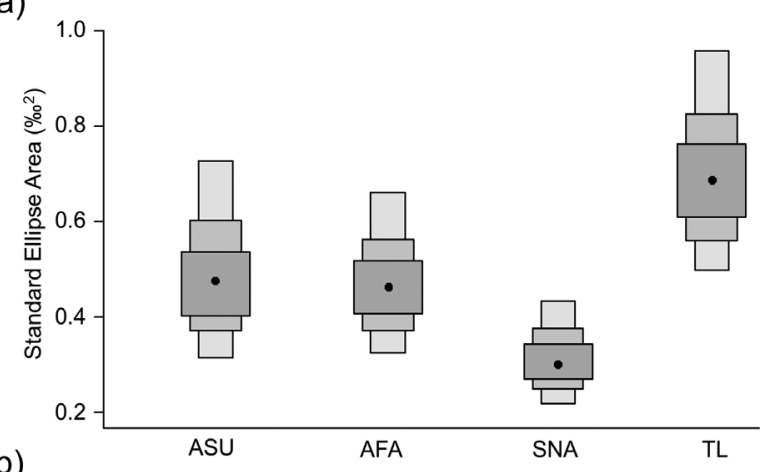

(b)

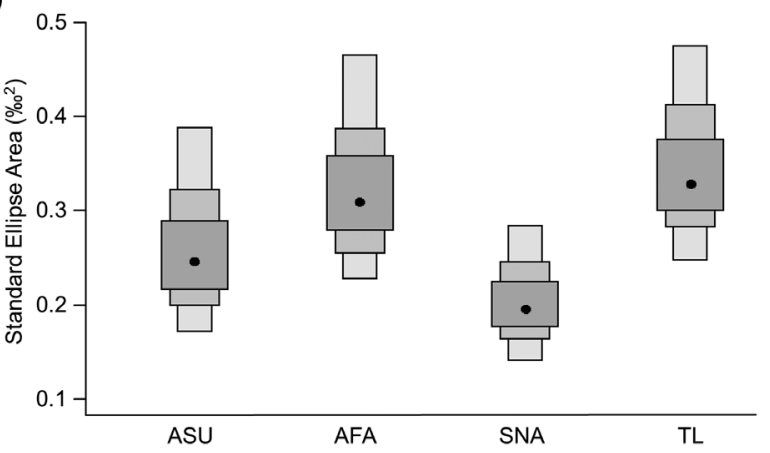

Figure 5. Boxplots of estimated models of standard ellipse areas $\left(\mathrm{SEA}_{\mathrm{B}}\right)$ for populations of Dascyllus abudafur from central Red Sea sites (ASU, AFA and SNA, from nearshore to offshore) and Madagascar (TL). A, $\mathrm{SEA}_{\mathrm{B}}$ when using raw isotopic data; $\mathrm{B}, \mathrm{SEA}_{\mathrm{B}}$ when using size-corrected isotopic data. The dark grey central box and the two lighter grey coloured boxes represent $50 \%, 75 \%$ and $95 \%$ confidence intervals, respectively, of the probability of the model's density distribution function. The black dots indicate the modes of these distributions. 
Table 4. Divergence (IDiv) and dispersion (IDis) indices of isotopic values for the four populations of Dascyllus abudafur from sites in the central Red Sea (ASU, AFA, SNA) and from Madagascar (TL)

\begin{tabular}{llllll}
\hline & & ASU & AFA & SNA & TL \\
\hline Raw isotopic data & IDiv & 0.68 & 0.70 & 0.68 & 0.82 \\
Size-corrected isotopic data & IDis & 0.38 & 0.47 & 0.31 & 0.49 \\
& IDiv & 0.66 & 0.70 & 0.73 & 0.69 \\
& IDis & 0.29 & 0.45 & 0.42 & 0.42 \\
\hline
\end{tabular}

Site abbreviations are given in Table 1.

Table 5. Pairwise comparisons among the four populations of Dascyllus abudafur from sites in the central Red Sea (ASU, AFA, SNA) and Madagascar (TL) using raw shape data and size-corrected shape data

\begin{tabular}{lccll}
\hline & ASU & AFA & SNA & TL \\
\hline Raw shape data & & & & \\
ASU & & $\mathbf{0 . 0 0 0 1}$ & $\mathbf{0 . 0 1 1}$ & $<\mathbf{0 0 0 1}$ \\
AFA & 0.026 & & $<\mathbf{0 . 0 0 0 1}$ & $<\mathbf{0 . 0 0 0 1}$ \\
SNA & 0.016 & 0.031 & & $<0.0001$ \\
TL & 0.053 & 0.069 & 0.059 & \\
Size-corrected shape data & & & & $\mathbf{0 . 0 0 0 1}$ \\
ASU & & $\mathbf{0 . 0 0 3}$ & $\mathbf{0 . 0 0 0 1}$ \\
AFA & 0.015 & & & $<0001$ \\
SNA & 0.018 & 0.026 & 0.050 & $<\mathbf{0 0 0 0 1}$ \\
TL & 0.046 & 0.048 & \\
\hline
\end{tabular}

Procrustes distances are below the diagonal and $P$-values are shown above the diagonal. Results are obtained by permutation tests $(N=10000)$. All differences were significant (bold). Site abbreviations correspond to those given in Table 1.

between sub-spaces defined by the first three principal components on shape variables corroborates the results from Mantel tests. Indeed, the angle between the sub-spaces of the four sites (i.e. Red Sea sites and Toliara) and the three Red Sea sites was always lower than the ranges of the within-subspace angles (Table 6). Consequently, we cannot reject the null hypothesis that the main axes of shape variation observed between the Red Sea and Toliara populations did not differ from those observed between the three Red Sea populations.

\section{DISCUSSION}

The present study provides evidence of trophic and morphological variation among populations of D. abudafur at a small spatial scale (along a crossshelf gradient inside the Red Sea), as well as between populations along a wider distribution range (Red Sea vs. Madagascar). We show that the same pattern of morphological variation repeatedly occurs at both spatial scales and that the D. abudafur population from Toliara lagoon is more diverse than the Red Sea populations.

\section{VARIATION IN THE TROPHIC ECOLOGY OF $D$. ABUDAFUR}

Results from the stomach content analyses are in line with previous observations (Frédérich et al., 2010) and, through these studies, we observe that $D$. abudafur shows trophic plasticity in response to differing environmental factors.

Several biotic and abiotic factors could explain the different trophic strategies of $D$. abudafur populations. Variation in competition, predation intensity, prey availability, turbidity and current speed are all potential factors influencing fish feeding strategies (e.g. Hugie \& Dill, 1994; Wellington et al., 2010). Our sites are characterized by different environmental conditions, which might determine the trophic ecology of $D$. abudafur. Individuals living in the clearest waters (SNA and ASU populations) feed mainly on zooplanktonic prey and our results suggest that one adaptive response of $D$. abudafur facing turbid waters is a trophic shift from almost exclusive zooplanktivory to a mixed diet of plankton and benthic prey (AFA and TL populations). However, we cannot reject the hypothesis that environmental factors other than 
(a)

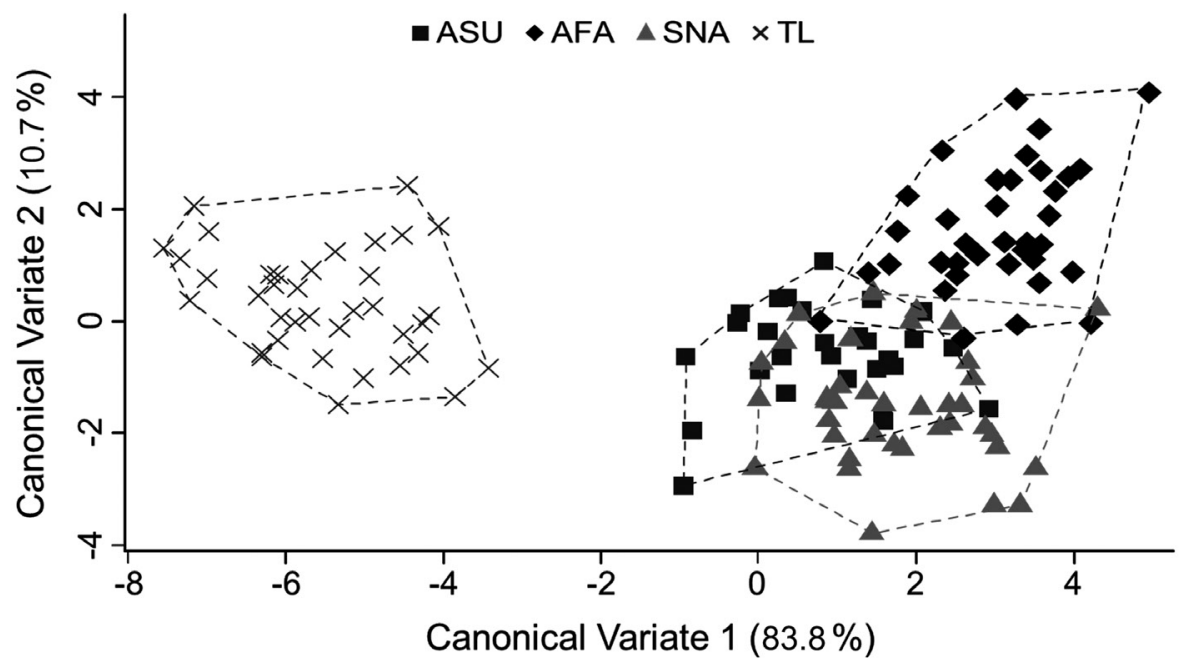

(b)

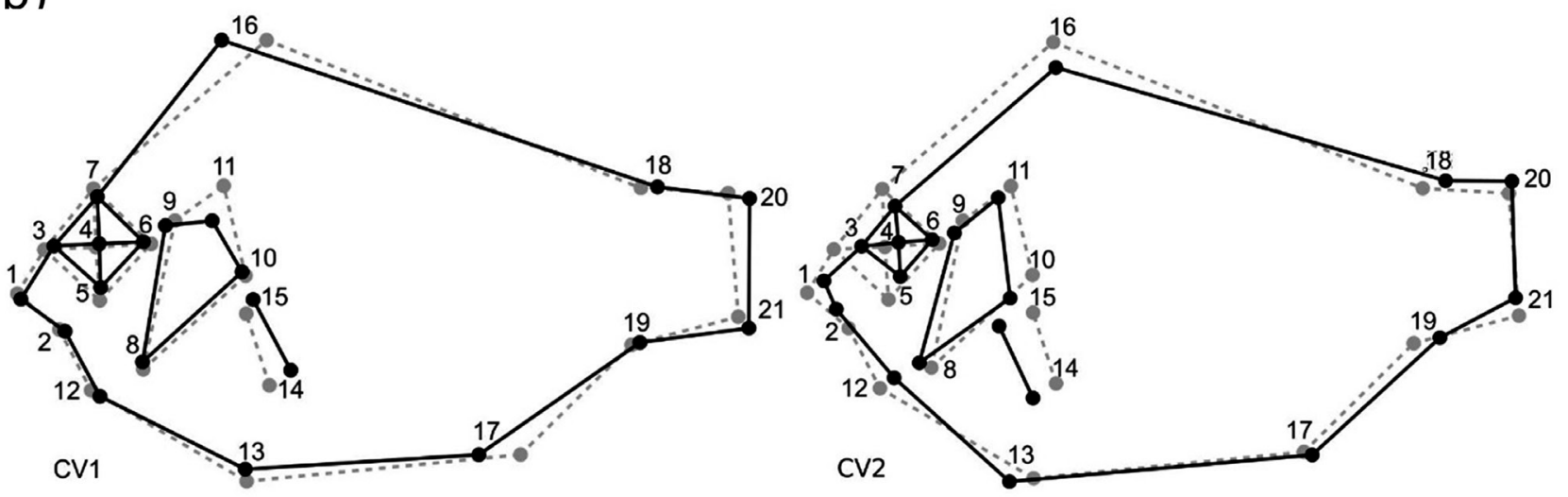

Figure 6. A, canonical analysis of the variation (CVA) in body shape of the four populations of Dascyllus abudafur (central Red Sea: ASU, AFA and SNA, from nearshore to offshore; and Madagascar: TL), when using raw shape data. Sites are indicated by different symbols and illustrated by convex envelopes (dotted outline). Site abbreviations are given in Table 1. $\mathrm{B}$, configuration points used to illustrate the variation in body shape along the first two CV axes, depicting shape variation from the lowest (black full line) to consensus (grey dotted line) values.

turbidity may also induce such a diet variation in D. abudafur. Individuals from AFA and TL fed on a larger proportion of benthic prey but the targeted benthic food items differ between sites: at TL lagoon, D. abudafur supplements its diet by eating small benthic crustaceans while it grazes plant materials at AFA. This difference could be explained by opportunism and/or further factors, which have yet to be studied.

Metrics of isotopic diversity agree with stomach contents, suggesting differences in trophic strategies among $D$. abudafur populations. Variation in isotopic niches is partially determined by the type of food source and by the isotopic variability of these food sources (Flaherty \& Ben-David, 2010; Lepoint et al., 2016). Accordingly, the highest contrasting isotopic values (IDis) from the AFA and TL populations might reflect their varied diet consisting of planktonic and benthic prey. On the other hand, the lowest isotopic richness of the SNA population suggests that, on this Red Sea site, $D$. abudafur feeds mainly on one type of trophic source: zooplanktonic copepods. Shib Nazar (SNA) is an offshore reef where the input of water column-based plankton is probably more constant than at the other sites (Wyatt et al., 2012) and this environmental condition could explain the smaller trophic variance of $D$. abudafur at this site. The trophic heterogeneity in the TL and AFA populations is by far the largest: three non-exclusive hypotheses can explain this difference compared to the SNA and ASU populations. First, a larger isotopic niche would be related to a larger diversity of ingested prey. The ingested benthic prey includes harpacticoid copepods, isopods, amphipods, polychaetes, filamentous algae and plant detritus (Table 3). This taxonomic diversity, 
which is larger than that among planktonic prey mainly constituted by copepods, may be linked to greater variability in isotopic values (Bodin et al., 2007;

(a)

(b)
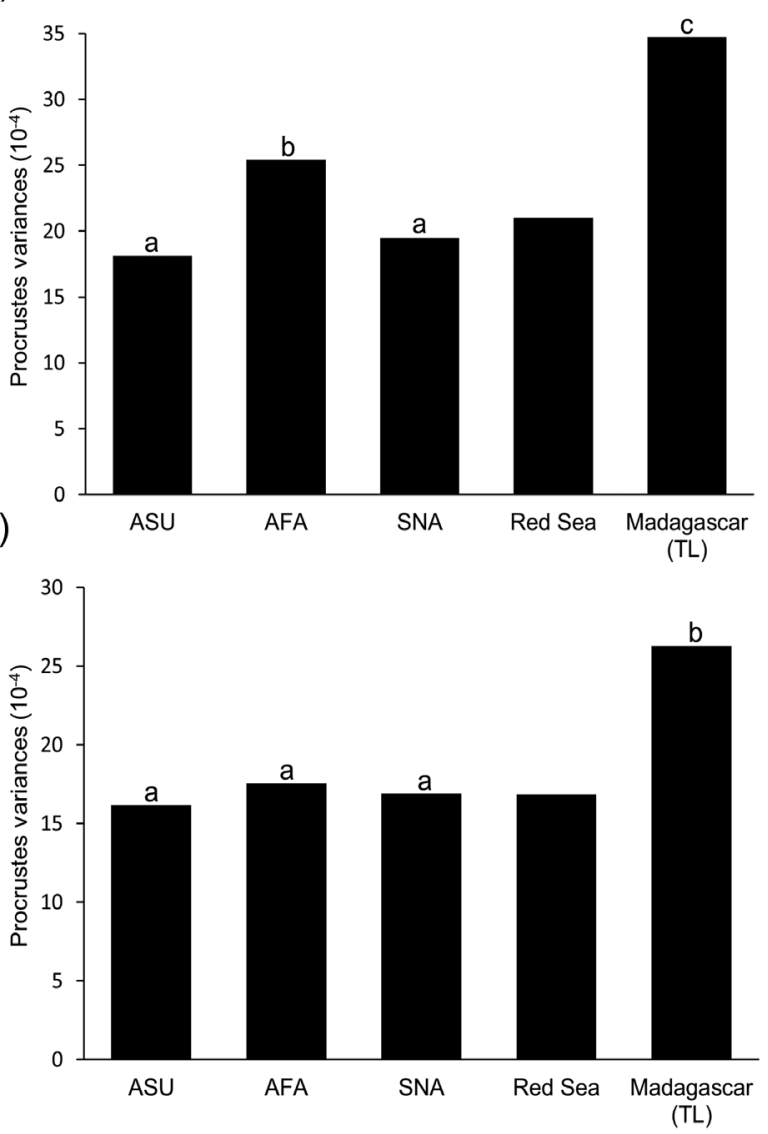

Figure 7. Levels of body shape disparity in the four studied populations and regions. Calculations of Procrustes variance were performed when using raw shape data (A) and size-corrected shape data (B). Letters at the top of the bar charts refer to group assessed on significant pairwise comparisons $(P<0.01)$ based on 9999 permutations. Site abbreviations are given in Table 1.
Frédérich et al., 2009). Secondly, these two populations could consist of specialized individuals whose trophic niches are subsets of the population's niche (Araújo et al., 2011). Thirdly, the seascape configuration of reefs could explain the variation in isotopic diversity. Indeed, the reef systems at Toliara and the central Red Sea are complex, with mangroves, seagrass beds and coral reefs interconnecting along the coastal zone. Differences in the connectedness of these habitats and in hydrodynamics may also explain the isotopic variability of food sources among sites.

\section{LINKS BETWEEN TROPHIC AND MORPHOLOGICAL VARIATION}

Our work provides further evidence that, beyond colour variation (e.g. Bernardi et al., 2002; Schultz et al., 2007), the morphology of coral reef fishes varies among sites showing different environmental conditions (present study; Frédérich et al., 2012b; Fulton et al., 2013; Binning et al., 2014; Binning \& Roche, 2015; Piñeros et al., 2015).

Interestingly, most morphological differences observed in D. abudafur populations are in agreement with their trophic divergence. The shape of the operculum differs between Red Sea and TL populations. In Red Sea populations, the operculum is narrower and proportionally higher than in individuals from Toliara. The wide variety in shape and size of the operculum in teleosts has been attributed to the important roles of this structure in food intake (Kimmel et al., 2008) and some ecomorphological studies have shown that the shape of the operculum can predict feeding habits in teleosts (Colombo et al., 2015; Wilson et al., 2015). Fish that feed through powerful suction usually have a dorso-ventrally flattened operculum that is anteroposteriorly wider than in fish feeding through the movement of their entire body and/or jaws towards the prey (Wilson et al., 2015). At Toliara, the shape of the operculum in D. abudafur suggests such an optimization of aspiration, probably used to dislodge benthic, vagile prey (Holzman et al., 2007, 2011).

Table 6. Comparisons of the patterns of shape disparity at large (Red Sea sites + Toliara) and small (Red Sea Sites) spatial scales

\begin{tabular}{|c|c|c|c|c|}
\hline Group 1 & Group 2 & Between groups (95\% CI) & Within group 1 & Within group 2 \\
\hline \multicolumn{5}{|l|}{ Raw shape data } \\
\hline Red Sea sites \& TL & Red Sea sites & $86(56-103)$ & 88 & 93 \\
\hline \multicolumn{5}{|c|}{ Size-corrected shape data } \\
\hline Red Sea sites \& TL & Red Sea sites & $89(64-111)$ & 90 & 94 \\
\hline
\end{tabular}

Results were obtained by bootstrapping procedures $(N=1600)$ using SpaceAngle8. Angles between the subspaces defined by the first three principal components on shape variables are in decimal degrees. The angle between subspaces is considered significant if it exceeds the bootstrapped withingroup variance at $95 \%$ confidence $(\mathrm{CI})$. 
Similarly, individuals living at the site with the lowest water visibility among Red Sea sites (i.e. AFA) have larger opercula, and their mouths are more ventrally oriented, which optimizes the capture of benthic prey. The insertion of the pectoral fins is more posterior in individuals from AFA and TL, also suggesting an optimization of manoeuvrability to forage close to the substratum (Webb, 1982; Ehlinger \& Wilson, 1988).

Eye size variation was not totally congruent with the above statement. We expected to observe fish phenotypes with larger eyes in more turbid waters (Pankhurst, 1989). However, our comparison at large spatial scale showed contradictory results, with Red Sea individuals having the largest eyes compared to those from the more turbid waters of Toliara (Fig. 6). On the other hand, at the scale of the central Red Sea, the eye size of $D$. abudafur increased with decreasing water visibility, as also observed in Dascyllus marginatus from the northern Red Sea (Brokovich et al., 2010). This leads to the question of why we find two different adaptive responses when fishes are living in turbid waters. Large eyes are characteristics of zooplanktivorous fishes (Pankhurst, 1989) and this trait might be crucial in oligotrophic waters. The increase in eye size, optimizing visibility at low light intensity (Fishelson et al., 2004), could operate as an adaptive response when variation in visibility is limited as across sites from central Red Sea. On the other hand, D. abudafur is also able to shift its foraging strategy and capture a higher proportion of benthic prey when the water is turbid (Fig. 3). This diversity of adaptation is probably driven by a combination of factors, such as prey availability, competition and predation pressure, which need further investigations.

Our data illustrate that the high level of isotopic diversity observed in the population of Toliara lagoon is related to the highest level of body shape disparity (Figs 5, 7). This congruence certainly supports the evidence of a higher level of trophic diversity in D. abudafur from Toliara and we also demonstrate that coral reef fish populations are not equal in terms of phenotypic diversity among sites and regions.

\section{LINKS BETWEEN PHENOTYPES AND GENOTYPES}

Our comparative analysis reveals that the main axes of body shape variation among populations are shared at both small (along a cross-shelf gradient in the Red Sea) and large (Madagascar and Red Sea sites) spatial scales. These results suggest that the factors underlying phenotypic variation are similar regardless of geographical location and are rather driven by environmental constraints. Two non-exclusive explanations can be considered:(1) the axes of variation which lead to the extrinsic selection of populations (i.e. the variation of environmental parameters) are limited and shared among populations, here the benthic-pelagic axis; and (2) some intrinsic constraints (e.g. genetic, development) control the direction of response to selection. The morphological evolution of damselfishes has already shown a limited range of phenotypic variation along the benthic-pelagic axis, leading to a tendency to repeat the rise of certain morphs even between different lineages (Cooper \& Westneat, 2009; Frédérich et al., 2013, 2016). The morphological variation in $D$. abudafur may represent this major common axis of ecological evolution in damselfishes. A common pattern of morphological variation may sustain the hypothesis that selection is acting on the same set of genes during the evolutionary history of $D$. abudafur populations. Phylogeographical studies have shown a genetic difference between the populations of the Red Sea and Madagascar (Liu et al., 2014). The fact that these populations at the large scale are also genetically distinct makes our study the first assessment of ecological and morphological features of these two genetic clades (Red Sea vs. south-western Indian Ocean).

To explain the significant morphological and trophic divergence observed at the small spatial scales among the Red Sea populations, we suggest a plastic response to different environmental conditions more than a genetically driven response. These geographical differences in $D$. abudafur further provide evidence of the adaptive advantage of ecological plasticity in trophic strategies, which may be one key component in species with wide biogeographical distributions. The Red Sea also provides an excellent experimental set-up, and a similar analytical approach could be applied to the endemic Red Sea species $D$. marginatus to assess whether phenotypic plasticity plays a different role among endemics and thus influences the geographical range of coral reef fishes (Robitzch et al., 2016).

\section{CONCLUSIONS}

The ecological and morphological variation observed in $D$. abudafur populations demonstrates that the reservoir of phenotypic diversity differs among coral reef sites and geographical regions. To some extent, the factors driving phenotypic variation in this species are analogous even over large biogeographical ranges and are probably given by environmental constraints. The drivers of phenotypic variation may not necessarily drive genetically distinct species. Therefore, studies on the evolution of coral reef fish populations should emphasize a combined approach using genetics and eco-morphological analyses to understand and discriminate between the micro-evolutionary processes working at different temporal, spatial and ecological scales. 


\section{ACKNOWLEDGEMENTS}

We thank Loïc N. Michel and Baptiste Le Bourg for their help with stable isotope analyses. We also thank the staff of the Institut Halieutique et des Sciences Marines (IH.SM) of Toliara and, particularly Prof. Richard Rasolofonirina and Prof. Thierry Lavitra for their welcome and their logistical help. Prof. Igor Eeckhaut is also acknowledged for giving us the opportunity to use BIOMAR facilities. We acknowledge Anna Roik for providing additional data on currents of the Red Sea sites. Finally, we thank the three anonymous reviewers for their helpful and constructive comments. Funding was provided by the 'Fonds National de la Recherche Scientifique of Belgium' (F.R.S-FNRS) to GL and BF. This research was supported by the KAUST baseline research funds \#BAS/1/1010-01-01 to MLB.

\section{REFERENCES}

Adams DC, Otárola-Castillo E. 2013. geomorph: an $\mathrm{R}$ package for the collection and analysis of geometric morphometric shape data. Methods in Ecology and Evolution 4: 393-399.

Aguilar-Medrano R, Frédérich B, de Luna E, Balart EF. 2011. Patterns of morphological evolution of the cephalic region in damselfishes (Perciformes: Pomacentridae) of the Eastern Pacific. Biological Journal of the Linnean Society 102: 593-613.

Aguilar-Medrano R, Frédérich B, Balart EF, De Luna E. 2013. Diversification of the pectoral fin shape in damselfishes (Perciformes, Pomacentridae) of the Eastern Pacific. Zoomorphology 132: 197-213.

Andréfouët S, Guillaume MMM, Delval A, Rasoamanendrika FMA, Blanchot J, Bruggemann JH. 2013. Fifty years of changes in reef flat habitats of the Grand Récif of Toliara (SW Madagascar) and the impact of gleaning. Coral Reefs 32: 757-768.

Araújo MS, Bolnick DI, Layman CA. 2011. The ecological causes of individual specialisation. Ecology Letters 14: 948-958.

Arfi R, Baklouti M, Bettarel Y, Blanchot J, Bouvier T, Bouvy M, Carré C, Champalbert G, Charpy L, Chevalier C, Corbin D, Devenon J-L, Garcia N, Got P, Langlade M-J, Leboulanger C, Lopé JC, Montel Y, Pagano M, Rodier M, Rabenavanana MW, Raimbault $\mathbf{P}$, Rougier G, Sarazin G. 2007. Impact des changements climatiques et anthropiques sur les flux trophiques du Grand Récif de Toliara, Madagascar (ICAR - GRT). In: Atelier de saison sèche. Madagascar: University contract, 2006/10301726. Final report, 52.

Barel CDN. 1982. Towards a constructional morphology of cichlid fishes (Teleostei, Perciformes). Netherlands Journal of Zoology 33: 357-424.

Barrow LM, Bjorndal KA, Reich KJ. 2008. Effects of preservation method on stable carbon and nitrogen isotope values. Physiological and Biochemical Zoology 81: 688-693.
Bernardi G, Holbrook SJ, Schmitt RJ, Crane NL, DeMartini E. 2002. Species boundaries, populations and colour morphs in the coral reef three-spot damselfish (Dascyllus trimaculatus) species complex. Proceedings of the Royal Society B: Biological Sciences 269: 599-605.

Binning SA, Roche DG. 2015. Water flow and fin shape polymorphism in coral reef fishes. Ecology 96: 828-39.

Binning SA, Roche DG, Fulton CJ. 2014. Localised intraspecific variation in the swimming phenotype of a coral reef fish across different wave exposures. Oecologia 174: 623-630.

Bodin N, LeLoc'h F, Hily C, Caisey X, Latrouite D, LeGuellec AM. 2007. Variability of stable isotope signatures $\left(\delta^{13} \mathrm{C}\right.$ and $\left.\delta^{15} \mathrm{~N}\right)$ in two spider crab populations (Maja brachydactyla) in Western Europe. Journal of Experimental Marine Biology and Ecology 343: 149-157.

Bolnick DI, Amarasekare P, Araújo MS, Bürger R, Levine JM, Novak M, Rudolf VHW, Schreiber SJ, Urban MC, Vasseur D. 2011. Why intraspecific trait variation matters in community ecology. Trends in Ecology \& Evolution 26: 183-192.

Bookstein FL. 1991. Morphometric tools for landmark data: geometry and biology. New York: Cambridge University Press.

Borsa P, Sembiring A, Fauvelot C, Chen W-J. 2014. Resurrection of Indian Ocean humbug damselfish, Dascyllus abudafur (Forsskål) from synonymy with its Pacific Ocean sibling, Dascyllus aruanus (L.). Comptes Rendus Biologies 337: 709-716.

Brokovich E, Ben-Ari T, Kark S, Kiflawi M, Dishon G, Iluz D, Shashar N. 2010. Functional changes of the visual system of the damselfish Dascyllus marginatus along its bathymetric range. Physiology \& Behavior 101: 413-421.

Bruggemann JH,Rodier M, Guillaume MMM,Andréfouët S, Arfi R, Cinner JE, Pichon M, Ramahatratra F, Rasoamanendrika F, Zinke J, McClanahan TR. 2012. Wicked social-ecological problems forcing unprecedented change on the latitudinal margins of coral reefs: the case of southwest Madagascar. Ecology and Society 17: 47.

Chevalier C, Devenon JL, Rougier G, Blanchot J. 2015. Hydrodynamics of the Toliara reef lagoon (Madagascar): example of a lagoon influenced by waves and tides. Journal of Coastal Research 316: 1403-1416.

Coates D. 1982. Some observations on the sexuality of humbug damselfish, Dascyllus aruanus (Pisces, Pomacentridae) in the field. Zeitschrift fur Tierpsychologie 59: 7-18.

Collyer ML, Sekora DJ, Adams DC. 2015. A method for analysis of phenotypic change for phenotypes described by high-dimensional data. Heredity 115: 357-365.

Colombo M, Damerau M, Hanel R, Salzburger W, Matschiner M. 2015. Diversity and disparity through time in the adaptive radiation of Antarctic notothenioid fishes. Journal of Evolutionary Biology 28: 376-394.

Cooper WJ, Westneat MW. 2009. Form and function of damselfish skulls: rapid and repeated evolution into a limited number of trophic niches. BMC Evolutionary Biology 9: 24.

Coplen TB. 2011. Guidelines and recommended terms for expression of stable-isotope-ratio and gas-ratio measurement 
results. Rapid Communications in Mass Spectrometry 25: 2538-2560.

Cucherousset J, Villéger S. 2015. Quantifying the multiple facets of isotopic diversity: new metrics for stable isotope ecology. Ecological Indicators 56: 152-160.

Ehlinger TJ, Wilson DS. 1988. Complex foraging polymorphism in bluegill sunfish. Proceedings of the National Academy of Sciences of the United States of America 85: $1878-1882$.

Fishelson L, Ayalon G, Zverdling A, Holzman R. 2004. Comparative morphology of the eye (with particular attention to the retina) in various species of cardinal fish (Apogonidae, Teleostei). The Anatomical Record 277A: 249-261.

Flaherty EA, Ben-David M. 2010. Overlap and partitioning of the ecological and isotopic niches. Oikos 119: 1409-1416.

Fleming NEC, Houghton JDR, Magill CL, Harrod C. 2011. Preservation methods alter stable isotope values in gelatinous zooplankton: implications for interpreting trophic ecology. Marine Biology 158: 2141-2146.

Frédérich B, Adriaens D, Vandewalle P. 2008. Ontogenetic shape changes in Pomacentridae (Teleostei, Perciformes) and their relationships with feeding strategies: a geometric morphometric approach. Biological Journal of the Linnean Society 95: 92-105.

Frédérich B, Colleye O, Lepoint G, Lecchini D. 2012a. Mismatch between shape changes and ecological shifts during the post-settlement growth of the surgeonfish, Acanthurus triostegus. Frontiers in Zoology 9: 8.

Frédérich B, Cooper WJ, Aguilar-Medrano R. 2016. Ecomorphology and iterative ecological radiation of damselfishes. In: Frédérich B, Parmentier E, eds. Biology of damselfishes. Boca Raton: CRC Press, 183-203.

Frédérich B, Fabri $G$, Lepoint $G$, Vandewalle $P$, Parmentier E. 2009. Trophic niches of thirteen damselfishes (Pomacentridae) at the Grand Récif of Toliara, Madagascar. Ichthyological Research 56: 10-17.

Frédérich B, Lehanse O, Vandewalle P, Lepoint G. 2010. Trophic niche width, shift, and specialization of Dascyllus aruanus in Toliara Lagoon, Madagascar. Copeia 2010: 218-226.

Frédérich B, Liu SYV, Dai CF. 2012b. Morphological and genetic divergences in a coral reef damselfish, Pomacentrus coelestis. Evolutionary Biology 39: 359-370.

Frédérich B, Olivier D, Litsios G, Alfaro ME, Parmentier E. 2014. Trait decoupling promotes evolutionary diversification of the trophic and acoustic system of damselfishes. Proceedings of the Royal Society B: Biological Sciences 281: 20141047.

Frédérich B, Sheets HD. 2010. Evolution of ontogenetic allometry shaping giant species: a case study from the damselfish genus Dascyllus (Pomacentridae). Biological Journal of the Linnean Society 99: 99-117.

Frédérich B, Sorenson L, Santini F, Slater GJ, Alfaro ME. 2013. Iterative ecological radiation and convergence during the evolutionary history of damselfishes (Pomacentridae). The American Naturalist 181: 94-113.

Frédérich B, Vandewalle P. 2011. Bipartite life cycle of coral reef fishes promotes increasing shape disparity of the head skeleton during ontogeny: an example from damselfishes (Pomacentridae). BMC Evolutionary Biology 11: 82.

Fricke HW, Holzberg S. 1974. Social units and hermaphroditism in a pomacentrid fish. Die Naturwissenschaften 61: 367-368.

Fulton CJ, Bellwood DR. 2005. Wave-induced water motion and the functional implications for coral reef fish assemblages. Limnology and Oceanography 50: 255-264.

Fulton CJ, Binning SA, Wainwright PC, Bellwood DR. 2013. Wave-induced abiotic stress shapes phenotypic diversity in a coral reef fish across a geographical cline. Coral Reefs 32: 685-689.

Gajdzik L, Parmentier E, Sturaro N, Frédérich B. 2016. Trophic specializations of damselfishes are tightly associated with reef habitats and social behaviours. Marine Biology 163: 249 .

Holzman R, Day SW, Wainwright PC. 2007. Timing is everything: coordination of strike kinematics affects the force exerted by suction feeding fish on attached prey. Journal of Experimental Biology 210: 3328-3336.

Holzman R, Collar DC, Mehta RS, Wainwright PC. 2011. Functional complexity can mitigate performance trade-offs. The American Naturalist 177: E69-E83.

Hugie DM, Dill LM. 1994. Fish and game: a game theoretic approach to habitat selection by predators and prey. Journal of Fish Biology 45: 151-169.

Hyslop EJ. 1980. Stomach contents analysis - a review of methods and their application. Journal of Fish Biology 17: 411-429.

Jackson AL, Inger R, Parnell AC, Bearhop S. 2011. Comparing isotopic niche widths among and within communities: SIBER - Stable Isotope Bayesian Ellipses in R. Journal of Animal Ecology 80: 595-602.

Johansen JL, Jones GP. 2013. Sediment-induced turbidity impairs foraging performance and prey choice of planktivorous coral reef fishes. Ecological Applications 23: 1504-1517.

Kaehler S, Pakhomov E. 2001. Effects of storage and preservation on the $\delta^{13} \mathrm{C}$ and $\delta^{15} \mathrm{~N}$ signatures of selected marine organisms. Marine Ecology Progress Series 219: 299-304.

Kelly B, Dempson JB, Power M. 2006. The effects of preservation on fish tissue stable isotope signatures. Journal of Fish Biology 69: 1595-1611.

Kimmel CB, Aguirre WE, Ullmann B, Currey M, Cresko WA. 2008. Allometric change accompanies opercular shape evolution in Alaskan threespine sticklebacks. Behaviour 145: 669-691.

Klingenberg CP. 2011. MorphoJ: an integrated software package for geometric morphometrics. Molecular Ecology Resources 11: 353-357.

Klingenberg CP. 2016. Size, shape, and form: concepts of allometry in geometric morphometrics. Development Genes and Evolution 226: 113-137.

Layman CA, Arrington DA, Montaña CG, Post DM. 2007. Can stable isotope ratios provide for community-wide measures of trophic structure? Ecology 88: 42-48. 
Lepoint G, Michel LN, Parmentier E, Frédérich B. 2016. Trophic ecology of the seagrass-inhabiting footballer demoiselle Chrysiptera annulata (Peters, 1855); comparison with three other reef-associated damselfishes. Belgian Journal of Zoology 146: 21-32.

Liem KF. 1993. Ecomorphology of the Teleostean skull. In: Hanken J, Hall BK, eds. The skull: functional and evolutionary mechanisms. Chicago: University of Chicago Press, 422-452.

Liu SYV, Chang FT, Borsa P, Chen WJ, Dai CF. 2014. Phylogeography of the humbug damselfish, Dascyllus aruanus (Linnaeus, 1758): evidence of Indo-Pacific vicariance and genetic differentiation of peripheral populations. Biological Journal of the Linnean Society 113: 931-942.

Manetta GI, Benedito E, Ducatti C. 2011. Effect of alcohol and formaldehyde on the $\delta^{13} \mathrm{C}$ and $\delta^{15} \mathrm{~N}$ isotopic composition of Plagioscion squamosissimus and Hypophthalmus edentates (Pisces, Osteichthyes). Acta Scientiarum. Biological Sciences 33: 393-397.

Monismith SG, Genin A, Reidenbach MA, Yahel G, Koseff JR. 2006. Thermally driven exchanges between a coral reef and the adjoining ocean. Journal of Physical Oceanography 36: 1332-1347.

Newsome SD, Martinez del Rio C, Bearhop S, Phillips DL. 2007. A niche for isotopic ecology. Frontiers in Ecology and the Environment 5: 429-436.

Newsome SD, Yeakel JD, Wheatley PV, Tinker MT. 2012. Tools for quantifying isotopic niche space and dietary variation at the individual and population level. Journal of Mammalogy 93: 329-341.

Pankhurst NW. 1989. The relationship of ocular morphology to feeding modes and activity periods in shallow marine teleosts from New Zealand. Environmental Biology of Fishes 26: 201-211.

Paradis E, Claude J, Strimmer K. 2004. APE: analyses of phylogenetics and evolution in R language. Bioinformatics 20: 289-290.

Pereira PHC, Moraes RL, dosSantos MVB, Lippi DL, Feitosa JLL, Pedrosa M. 2014. The influence of multiple factors upon reef fish abundance and species richness in a tropical coral complex. Ichthyological Research 61: 375-384.

Piñeros VJ, Rios-Cardenas O, Gutiérrez-Rodríguez C, Mendoza-Cuenca L. 2015. Morphological differentiation in the damselfish Abudefduf saxatilis along the Mexican Atlantic coast is associated with environmental factors and high connectivity. Evolutionary Biology 42: 235-249.

Pugh DT, Abualnaja Y, Jarosz E. 2019. The tides of the Red Sea. In: Rasul N, Stewart I, eds. Oceanographic and biological aspects of the Red Sea. Cham: Springer, 11-40.

Randall HA, Allen GR. 1977. A revision of the damselfish genus Dascyllus (Pomacentridae) with the description of a new species. Records of the Australian Museum 31: 349-385.

R Development Core Team. 2013. $R$ : a language and environment for statistical computing. Vienna: R Foundation for Statistical Computing. http://www.R-project.org.

Reidenbach MA, Monismith SG, Koseff JR, Yahel G, Genin A. 2006. Boundary layer turbulence and flow structure over a fringing coral reef. Limnology and Oceanography 51: 1956-1968.

Robertson DR. 1985. Sexual size dimorphism in surgeon fishes. Proceedings of the Fifth International Coral Reef Congress 5: 403-408.

Robitzch VSN, Lozano-Cortés D, Kandler NM, Salas E, Berumen ML. 2016. Productivity and sea surface temperature are correlated with the pelagic larval duration of damselfishes in the Red Sea. Marine Pollution Bulletin 105: 566-574.

Roik A, Röthig T, Roder C, Ziegler M, Kremb SG, Voolstra CR. 2016. Year-long monitoring of physicochemical and biological variables provide a comparative baseline of coral reef functioning in the central Red Sea. PLoS ONE 11: e0163939.

Rundell RJ, Price TD. 2009. Adaptive radiation, nonadaptive radiation, ecological speciation and nonecological speciation. Trends in Ecology \& Evolution 24: 394-399.

Sale PF. 1971. Extremely limited home range in a coral reef fish, Dascyllus aruanus (Pisces; Pomacentridae). Copeia 1971: 324-327.

Schultz JK, Pyle RL, DeMartini E, Bowen BW. 2007. Genetic connectivity among color morphs and Pacific archipel- agos for the flame angelfish, Centropyge loriculus. Marine Biology 151: 167-175.

Shulman MJ. 1984. Resource limitation and recruitment patterns in a coral reef fish assemblage. Journal of Experimental Marine Biology and Ecology 74: 85-109.

Vizza C, Sanderson BL, Burrows DG, Coe HJ. 2013. The effects of ethanol preservation on fish fin stable isotopes: does variation in C:N ratio and body size matter? Transactions of the American Fisheries Society 142: 1469-1476.

Wainwright PC, Bellwood DR. 2002. Ecomorphology of feeding in coral reef fishes. In: Sale PF, ed. Coral reef fishes. Dynamics and diversity in a complex ecosystem. San Diego: Academic Press, 33-55.

Webb PW. 1982. Locomotor patterns in the evolution of actinopterygian fishes. American Zoologist 22: 329-342.

Wellington CG, Mayer CM, Bossenbroek JM, Stroh NA. 2010. Effects of turbidity and prey density on the foraging success of age 0 year yellow perch Perca flavescens. Journal of Fish Biology 76: 1729-1741.

Whitney JL, Donahue MJ, Karl SA. 2018. Niche divergence along a fine-scale ecological gradient in sympatric color morphs of a coral reef fish. Ecosphere 9: e02015.

Wilson LAB, Colombo M, Sáchez-Villagra MR, Salzburger W. 2015. Evolution of opercle shape in cichlid fishes from Lake Tanganyika - adaptive trait interactions in extant and extinct species flocks. Scientific Reports 5: 16909.

Wyatt ASJ, Waite AM, Humphries S. 2012. Stable isotope analysis reveals community-level variation in fish trophodynamics across a fringing coral reef. Coral Reefs 31: 1029-1044.

Zelditch ML, Swiderski DL, Sheets HD, Fink WL. 2012. Geometric morphometrics for biologists: a primer. Amsterdam: Elsevier Academic Press. 


\section{SUPPORTING INFORMATION}

Additional Supporting Information may be found in the online version of this article at the publisher's web-site.

Figure S1. Histogram illustrating the size of the convex hulls and the standard ellipse areas for populations of Dascyllus abudafur from sites inside the central Red Sea (ASU, AFA and SNA, from shore to shelf-edge, respectively) and from Madagascar (TL), when using (a) raw isotopic data and (b) size-corrected isotopic data.

Figure S2. (a) Canonical analysis of the variation (CVA) in body shape of the four populations of Dascyllus abudafur (central Red Sea: ASU, AFA and SNA, from nearshore to offshore; and Madagascar: TL), when using size-corrected shape data. Convex envelopes (dotted outline) are used to illustrate the four populations. Reef sites are indicated by different symbols and the abbreviations are given in Table 1. (b) Configuration points and lines used to illustrate the variation in body shape along the two CV axes, depicting shape variation from the lowest to consensus values (represented by black full line and grey dotted line respectively). 